\title{
Editorial
}

\section{Saúde Mental: novas perspectivas}

| Kenneth R. de Camargo Jr. |

Nesta edição de Physis, temos mais uma vez um tema organizado a partir da demanda espontânea, abordando questôes historicamente caras à revista. As transformações na política de atenção à Saúde Mental nascem de um ideário fértil e generoso, a Reforma Psiquiátrica, mas ainda se encontram distantes de sua plena implementação. Não obstante, criaram-se espaços de experimentação e inovação que vêm se estendendo e articulando tal ideário na concretude de práticas cotidianas. Os três artigos do tema abordam objetos diversos, mas trazem em comum um olhar inovador com a possibilidade de importantes contribuições para o aperfeiçoamento das ações de Saúde Mental em nosso país.

Paranhos-Passos e Aires apresentam a visão de usuários de um CAPS sobre a reinserção social, mostrando que ainda há um longo caminho a percorrer para que esta de fato seja compreendida e aceita de forma ampla. Borysow e Furtado analisam o acompanhamento de pessoas com transtornos mentais graves e sem domicílio, ressaltando a importância do fortalecimento de ações intersetoriais para dar conta da complexidade dessa situação. Encerrando o tema, Alves e colaboradores relatam diferentes concepções sobre o empoderamento de diversos atores na saúde mental, trazendo considerações sobre as repercussões de tais concepções para a própria assistência.

Abrindo a seção de temas livres, Pinheiro e Couto abordam a relação entre integralidade e gênero na atenção primária. Fontenele e Tanaka apresentam a visão de mulheres que sofreram esterilização cirúrgica que buscam a reprodução assistida. Rocha e Uchoa analisam a possibilidade de avaliação da atenção humanizada ao abortamento.

Segue-se o trabalho de Taquette e Meirelles, que estudam as repercussões da discriminação racial na vulnerabilidade ao HIV/Aids. Pombo-de-Barros e 
colaboradores apresentam as representaçôes de cidadania de um conjunto de senadores brasileiros. Silva discute o trabalho de Ramachandran sobre membrosfantasma na elucidação da construção da imagem corporal. Fragelli e Shimizu avaliam o potencial de formação de profissionais de saúde a partir do panorama apresentado pelos grupos de pesquisa do CNPq.

Mendes e colaboradores identificaram a complexa rede de lideranças locais que desempenham papel-chave para a proposição e implementação de medidas de melhoria da qualidade de vida dos cidadãos. Silva e colaboradores trazem os resultados de pesquisa que avalia a percepção de pacientes sobre a terapêutica da hipertensão arterial. Vieira e colaboradores apresentam a experiência de implantação de serviços de genética médica no SUS. Encerrando a seção, Arbex e colaboradores descrevem e analisam os sentidos da readaptação laboral na visão de professores universitários que passaram por esse processo.

Encerrando este número, temos as resenhas de Mattos sobre o Dictionnaire du Corps, de Andrieu e Boetsch, e a de Silva e Ferreira sobre Sobrevivendo ao estigma da gordura, de Mattos.

\section{Mudanças da Physis}

$\mathrm{Na}$ passagem de 2012 para 2013, tivemos algumas mudanças na editoria da revista. Não mais contamos com a colaboração de Octávio Bonnet, a quem agradecemos e desejamos felicidades nos seus novos caminhos. Agregamos novas editoras associadas, Carla Ribeiro Guedes, Rafaela Zorzanelli e Rosângela Caetano, que já assumiram as novas tarefas com enorme dedicação. Célia Pierantoni assumiu a editoria de resenhas, substituindo Jane Sayd, a quem também agradecemos e desejamos boa sorte. Finalmente, Ana Silvia Gesteira passa a ser nossa editora assistente, em reconhecimento à sua contribuição e dedicação à nossa revista, bem como ao papel-chave que efetivamente desempenha.

Realizamos algumas mudanças também no processo de submissão de artigos: seguindo recomendações de comitê do CNPq, que discutiu e propôs normas relativas à ética e integridade na pesquisa, baseando-se, entre outros, no trabalho do International Committee of Medical Journal Editors, passamos a solicitar um novo formato de declaração de autoria, no qual deve ser especificada a contribuição individual de cada autor. Estamos usando os mesmos critérios 
para avaliar a pertinência da atribuição de autoria e revisamos juntamente com

os autores a declaração, o que tem levado a cortes no número de autores por artigo em vários casos.

Temos assistido a uma verdadeira inflação do número de autores, nem sempre justificada, e pedimos a atenção de todos para esse problema; uma abordagem leviana, mesmo que não sendo necessariamente mal-intencionada, da atribuição de autoria, pode levar à perda do seu valor. Em vários casos (que por razões éticas não podemos exemplificar), vemos situações que beiram o absurdo, com uma proliferação de autores cujo número, por vezes, chega a se aproximar ou mesmo ultrapassar o total de sujeitos da pesquisa descrita no artigo.

Reconhecemos que há situações que justificam um número elevado de autores de um manuscrito, mas essas devem ser justificadas e certamente não são frequentes no nosso domínio temático. A linha editorial da revista, que privilegia as áreas de Ciências Sociais e Humanas e de Política e Planejamento no campo da Saúde Coletiva, historicamente conta com trabalhos fortemente autorais, com número limitado de coautores, com as exceções de praxe. Quando vemos a exceção ameaçar tornar-se regra, sem que nada de substantivo, epistemológica ou metodologicamente, tenha mudado nessas áreas, isso se torna motivo de preocupação.

Estamos tentando também agilizar o processo de revisão de textos, que está em vários casos tomando um tempo muito além do razoável. À parte o agravamento da dificuldade em conseguir revisores, só recentemente detectamos problemas no sistema de gerenciamento de manuscritos que impactaram negativamente nosso fluxo de trabalho. Caso, por exemplo, haja problemas no envio de e-mails, ou o revisor convidado não responda no prazo determinado para dizer se aceita ou não, o sistema não gera nenhuma notificação para nós. A SciELO ofereceu um novo sistema de gerenciamento, que aceitamos, mas não há ainda previsão de quando o mesmo será de fato implementado. Cientes do problema, estamos tentando superá-lo da melhor forma possível.

Adicionalmente, passaremos de fato a exercitar uma determinação que já havíamos estabelecido anteriormente: manuscritos que não sigam as normas do processo de submissão serão arquivados sem revisão. Temos recebido com frequência artigos com identificação dos autores, ou com a documentação suplementar incompleta ou ausente. Isso tem demandado um tempo crescente 
da editoria, às vezes com várias idas e vindas até os autores cumprirem as normas, por vezes gerando novo registro para um artigo em processamento e complicando mais ainda a gestão de um sistema com limitações importantes. Sendo assim, pedimos a compreensão dos autores, mas passaremos a cumprir o que já havíamos determinado. $\mathrm{O}$ arquivamento por violação das normas não impede nova submissão do mesmo manuscrito, desde que os problemas identificados sejam corrigidos. Pedimos a compreensão dos nossos colaboradores. 